\title{
EFFECT OF Zr PURITY AND OXYGEN CONTENT ON THE STRUCTURE AND MECHANICAL PROPERTIES OF MELT-SPUN AND SUCTION-CAST $\mathrm{Cu}_{46} \mathrm{Zr}_{42} \mathrm{Al}_{7} \mathrm{Y}_{5}$ ALLOY
}

\begin{abstract}
The effect of oxygen content in zirconium on the structure and mechanical properties of the $\mathrm{Cu}_{46} \mathrm{Zr}_{42} \mathrm{Al}_{7} \mathrm{Y}_{5}$ alloy, in the form of melt-spun ribbons and suction-cast rods, was investigated. Two types of $\mathrm{Zr}$, rod and crystal bar of different nominal purities and oxygen contents, were used to synthesize the alloy by arc melting. Rapidly solidified ribbons were produced by melt spinning and their amorphous structures were confirmed by X-ray diffractometry (XRD) and differential scanning calorimetry (DSC). Bulk samples in the form of rods were cast using a special water-cooled suction casting unit attached to the arc melting system. XRD and DSC studies proved the amorphous structure of the bulk alloy synthesized from low-oxygen $\mathrm{Zr}$ and partial crystallization of the same alloy for high-oxygen Zr. In both bulk samples, uniformly distributed crystalline particles were identified as yttrium oxides. Higher mean compressive strength of amorphous alloy was observed. The hardness of amorphous phase was close to 500 HV1 in both bulk alloys, while the hardness of crystalline dendritic areas, observed in the alloy synthesized from high oxygen $\mathrm{Zr}$, was lower by about $50 \mathrm{HV} 1$.

Keywords: metallic glasses, bulk metallic glasses, melt spinning, suction casting
\end{abstract}

\section{Introduction}

Bulk metallic glasses (BMGs) are an important part of materials science field. A huge scientific interest arises from their extraordinary physical, chemical and mechanical properties as compared to their crystalline counterparts. BMGs combine high elastic limit, high strength, corrosion resistance and excellent castability [1-3]. Over the past decades, the critical size increased from micrometer to centimeter level for the best glass-forming systems $[1,4,5]$. However, synthesis of monolithic BMGs requires use of high purity precursors and strict processing conditions, which increases the manufacturing cost and limits their possible applications. High purity is a general term, but the most important issue is the oxygen content. A certain amount of oxygen, which originates from the impurity of raw materials, is always dissolved in Zr-based alloys [6]. Despite high solubility of oxygen in $\mathrm{Zr}$, which is about 30 at. $\%$ at $200^{\circ} \mathrm{C}$ [7], this element was recognized as the main barrier to vitrification of $\mathrm{Zr}$-based alloys. Oxygen-induced precipitation of metastable quasicrystalline phases has been confirmed in a number of Zr-based BMGs [8-11], leading to severe deterioration of glass-forming abilities, thermal stabilities and mechanical properties. The crystallization time decreases by an order of magnitude (at a given undercooling temperature) with increasing oxygen content from 250 to $5250 \mathrm{ppm}$ in the $\mathrm{Zr}_{52.5} \mathrm{Ti}_{5} \mathrm{Cu}_{17.9} \mathrm{Ni}_{14.6} \mathrm{Al}_{10}$ (Vit105) alloy [12]. Rare-earth elements, which exhibit higher chemical affinities to oxygen than zirconium, are attributed to hamper the negative effect of oxygen [13-16].

Some authors report beneficial role of oxygen presence in BMGs. Wang et al. suggest that this element should be considered as an alloying element rather than an impurity, because it can be dissolved uniformly in a glassy phase and enhance the glass-forming ability [17]. Similar reports are presented by Cheng and co-workers [18-20], who obtained bulk amorphouscrystalline composites in the $\mathrm{Zr}$-based metallic glass using low grade industrial raw materials processed under industrial vacuum systems. The oxygen was absorbed and concentrated only in the precipitated $b-\mathrm{Zr}$ phase, resulting in the remaining molten alloy retaining good glass forming ability [19].

This paper presents structures and mechanical properties of the $\mathrm{Cu}_{46} \mathrm{Zr}_{42} \mathrm{Al}_{7} \mathrm{Y}_{5}$ alloy in the form of ribbons and rods, synthesized from two types of $\mathrm{Zr}$ of different purities and oxygen content.

\section{Experimental procedure}

Alloys with a nominal composition of $\mathrm{Cu}_{46} \mathrm{Zr}_{42} \mathrm{Al}_{7} \mathrm{Y}_{5}$ (at. $\%$ ) were synthesized by arc melting (Edmund Bühler Arc Melter AM). This method is suitable for synthesis of most metallic alloys, including glass-forming alloys [21], high entropy [22] and conventional crystalline Fe-based alloys [23]. The elemental

\footnotetext{
* AGH UNIVERSITY OF SCIENCE AND TECHNOLOGY, FACULTY OF METALS ENGINEERING AND INDUSTRIAL COMPUTER SCIENCE, 30 MICKIEWICZA AL., 30-059 KRAKOW, POLAND ** WARSAW UNIVERSITY OF TECHNOLOGY, FACULTY OF MATERIALS SCIENCE AND ENGINEERING, 141 WOŁOSKA STR., 02-507 WARSAW, POLAND

*** AGH UNIVERSITY OF SCIENCE AND TECHNOLOGY, ACADEMIC CENTRE FOR MATERIALS AND NANOTECHNOLOGY, 30 MICKIEWICZA AL., 30-059 KRAKOW, POLAND 
$\mathrm{Cu}$ (purity of 99.995\%), Zr, Al (99.999\%), Y (99.9\%) and $\mathrm{Zr}$ $(99.8 \%$ or $99.5 \%)$ in two forms, rod and crystal bar, were used for alloy synthesis.

Zr rod was of nominal purity $99.8 \%$ (including $2.1 \mathrm{wt} \%$ Hf) and nominally contained $0.06 \mathrm{wt} \% \mathrm{Fe}+\mathrm{Cr}, 0.06 \mathrm{wt} \% \mathrm{C}$ and $0.12 \mathrm{wt} \%$ of oxygen. Zirconium and hafnium are chemically similar elements and it is very difficult to separate $\mathrm{Hf}$ from $\mathrm{Zr}$ scrap. Moreover high purity Zr, with oxygen content below 100 ppm, is regarded as the only material that can be used as a cladding material for nuclear fuel because it has the lowest neutron capture cross section of any metal element [24]. Therefore high purity $\mathrm{Zr}$, with oxygen below $100 \mathrm{ppm}$ and $\mathrm{Hf}$ free, is not commercially available. Inoue et al. [25] have studied the effect of alloying in Zr-based glass-forming systems with different metals (Ti, Hf, V, $\mathrm{Nb}, \mathrm{Cr}, \mathrm{Mo}, \mathrm{Fe}, \mathrm{Co}, \mathrm{Pd}, \mathrm{Ag})$. Hafnium, unlike other elements, did not affect glass forming ability of the base alloy, even for Hf concentration as high as 15 at.\%.

The $\mathrm{Zr}$ crystal bar of nominal purity of $99.5 \%$ and, according to the certificate, contained low concentrations (max. $100 \mathrm{ppm}$ ) of many elements, including $40 \mathrm{ppm} \mathrm{Hf}$ and only 103 ppm of oxygen.

Before melting process, the chamber was first evacuated to $<5 \times 10^{-2}$ mbar, backfilled with high purity (6N) Ar and reevacuated. The backfill-evacuation cycle was performed three times to minimize an oxygen level in the chamber. After the third evacuation, the chamber was evacuated to $<5 \times 10^{-5}$ mbar using a turbomolecular pump. The melting process was carried out at a partial pressure of Ar and the melt solidified on a watercooled $\mathrm{Cu}$ hearth. Each sample was melted four times to ensure homogeneous mixing.

The alloys were rapidly solidified by the melt spinning method (Edmund Bühler melt spinner HV). The ingots were induction remelted in a quartz tube, followed by ejection (argon over-pressure $50 \mathrm{kPa}$ ) through an orifice onto a rotating copper wheel (linear wheel speed $40 \mathrm{~m} / \mathrm{s}$ ). The ribbon thickness was about $30 \mu \mathrm{m}$.

Cylindrical samples, with diameters of $3 \mathrm{~mm}$ and lengths $55 \mathrm{~mm}$, were prepared using a special water-cooled suction casting unit. In this method an arc melted alloy is sucked into a copper mould containing a cylindrical cavity. The minimum axial cooling rate for $3 \mathrm{~mm}$ diameter rods was previously estimated as $\sim 200^{\circ} \mathrm{K} / \mathrm{s}$ [26].

Transverse cross sections of as-cast samples were analyzed by $\mathrm{X}$-ray diffraction using $\mathrm{Cu}-\mathrm{Ka}$ radiation (Siemens D500). Differential scanning calorimetry at a constant heating rate of $20^{\circ} \mathrm{K} / \mathrm{min}$ was used to study the crystallization behaviour (Perkin Elmer Pyris Diamond DSC). Microstructural observations of bulk samples were carried out on polished cross sections of rods (final polishing with colloidal silica suspension) using optical microscopy and scanning electron microscopy (FEI Versa 3D) equipped with the energy dispersive spectroscopy (EDS) detector. SEM images were recorded using a backscattered electron (BSE) detector. Compression tests were carried out on a universal testing machine Instron 5982 with an initial strain rate of $1 \cdot 10^{-4} \mathrm{~s}^{-1}$. Mean values and standard deviations were evaluated based on three compressed samples for SC-LO and SC-HO samples. The height-to-diameter aspect ratio of the bulk compression specimens was kept to 2.0. Both ends of the specimens were carefully polished to make them parallel.

Vickers hardness HV1 was measured on cross sections of rods using a computer controlled Wilson-Hardness Tukon 2500 hardness tester.

The oxygen content of $\mathrm{Zr}$ metal was measured by inert gas fusion method using Leco RO400C and revealed $1317 \pm 10 \mathrm{ppm}$ $\mathrm{O}_{2}$ for $99.8 \% \mathrm{Zr}$ rod and $175 \pm 40 \mathrm{ppm} \mathrm{O}_{2}$ for $99.5 \% \mathrm{Zr}$ crystal bar. The sample names, both in form of melt-spun ribbons (MS) and suction-cast (SC) rods, relate to oxygen content in both types of $\mathrm{Zr}$, and are herein referred to as $\mathrm{HO}$ (High Oxygen) and LO (Low Oxygen), respectively.

\section{Results}

Figure 1 shows the XRD patterns of the melt-spun (Fig. 1a) and suction-cast (Fig. 1b) alloys. Broad diffraction maxima were noticed for the rapidly solidified (MS-LO, MS-HO) ribbons
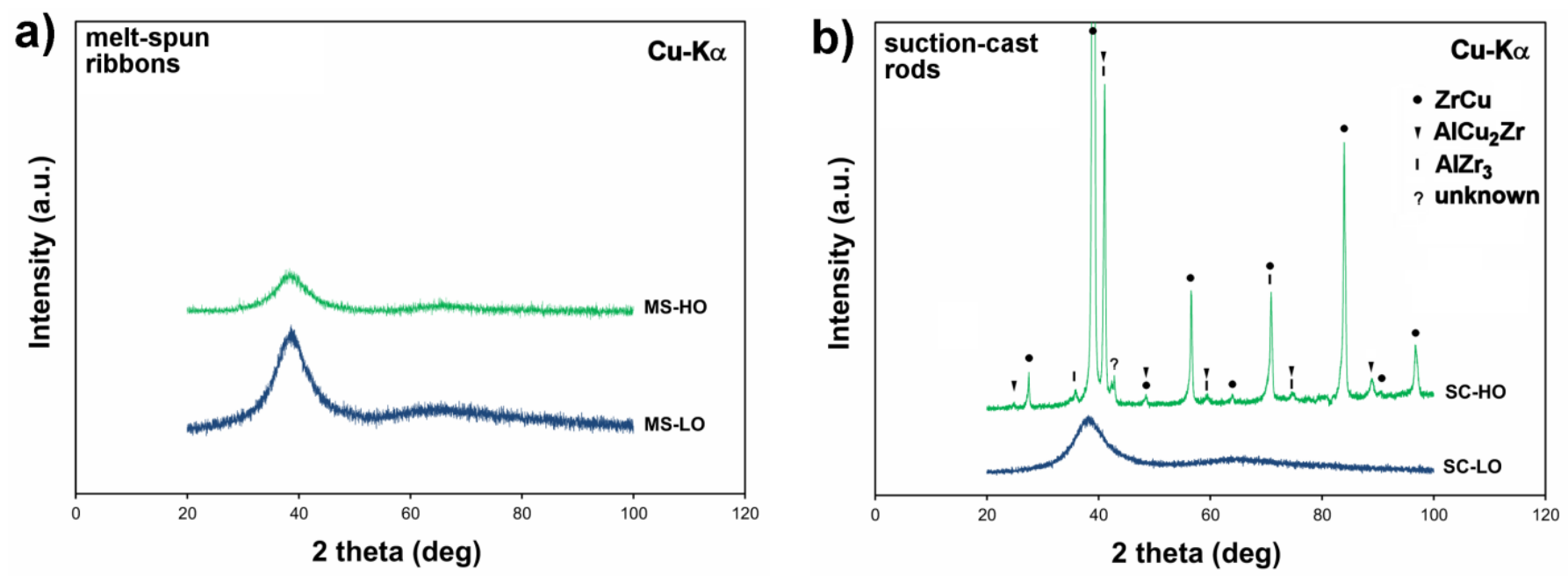

Fig. 1. XRD patterns of the a) melt-spun and b) suction cast $\mathrm{Cu}_{46} \mathrm{Zr}_{42} \mathrm{Al}_{7} \mathrm{Y}_{5}$ alloys 
as well as for the suction-cast alloy made from low oxygen $\mathrm{Zr}$ (SC-LO). On the other hand, for the bulk sample synthesized from high oxygen $\mathrm{Zr}$ (SC-HO) sharp Bragg peaks were noticed, corresponding the presence of crystalline $\mathrm{ZrCu}$ (cubic, space group $\mathrm{Pm} 3 \mathrm{~m}$, lattice parameter 3.22 $\AA$ ), $\mathrm{AlCu}_{2} \mathrm{Zr}$ (cubic, Fm3m, $6.22 \AA$ ) and $\mathrm{AlZr}_{3}$ (cubic, $\mathrm{Fm} 3 \mathrm{~m}, 4.38 \AA$ ) phases.

The DSC curves of the alloys in form of ribbons and rods are presented in (Fig. 2a,b), respectively. Three stage crystallization of the amorphous phase was noticed for all samples. No distinct glass transition $\left(T_{g}\right)$ temperatures could be determined for the alloys synthesized from the high oxygen zirconium, both in form of ribbon (MS-HO) and rod (SC-HO). For the ribbon synthesized from low oxygen $\mathrm{Zr}$ (MS-LO), a supercooled liquid region $\Delta T_{x}$, being a difference between onset crystallization $\left(T_{\chi}\right)$ and glass transition temperature, was estimated to be about $15^{\circ} \mathrm{K}$ (Fig. 2a). Similar crystallization behaviour was observed for the bulk samples (Fig. 2b). Results of DSC investigations are summarized in Table 1.
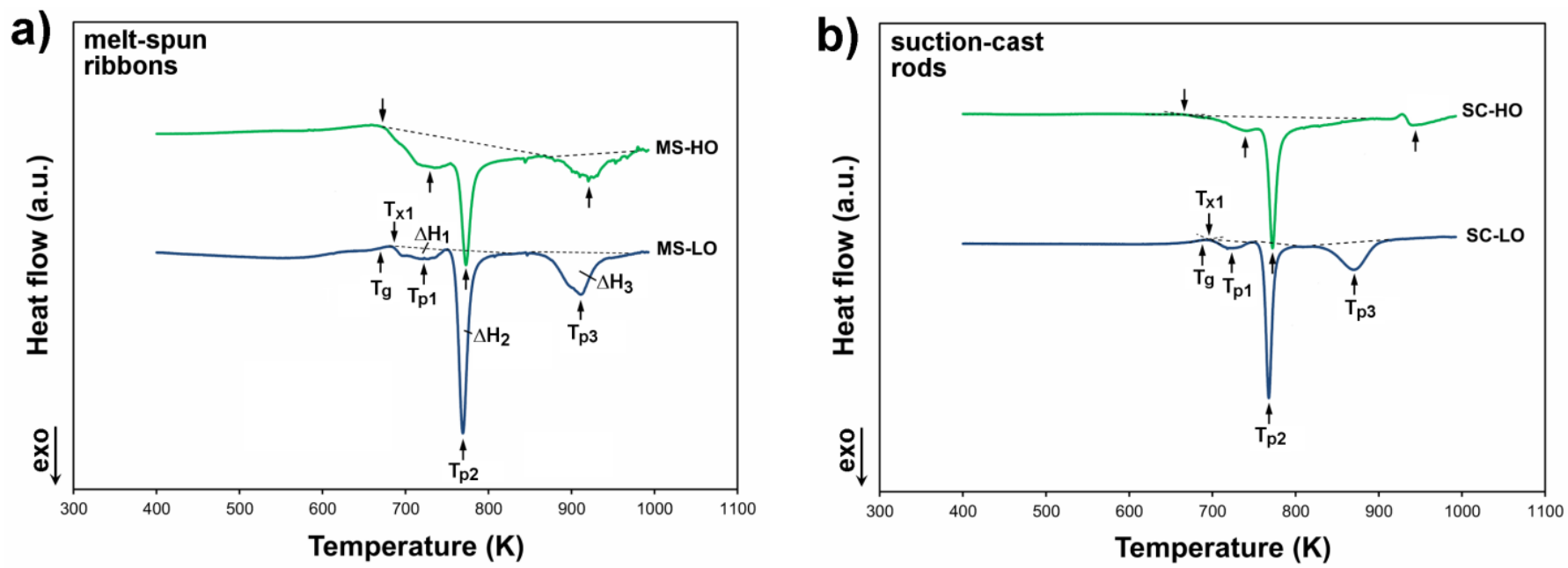

Fig. 2. DSC curves of the a) melt-spun and b) suction cast $\mathrm{Cu}_{46} \mathrm{Zr}_{42} \mathrm{Al}_{7} \mathrm{Y}_{5}$ alloys recorded at a heating rate of $20^{\circ} \mathrm{K} / \mathrm{min}$.

TABLE $1 \quad \mathrm{MPa}$ and $1431 \mathrm{MPa}$, respectively. No plastic deformation was Details of DSC investigations for melt-spun (MS) and suction-cast (SC) alloys

\begin{tabular}{|l|c|c|c|c|c|c|c|c|}
\hline \hline & $\begin{array}{c}\boldsymbol{T}_{\boldsymbol{g}} \\
\left({ }^{\circ} \mathbf{K}\right)\end{array}$ & $\begin{array}{c}\boldsymbol{T}_{\boldsymbol{x} 1} \\
\left({ }^{(} \mathbf{K}\right)\end{array}$ & $\begin{array}{c}\boldsymbol{T}_{\boldsymbol{p} 1} \\
\left({ }^{\circ} \mathbf{K}\right)\end{array}$ & $\begin{array}{c}\boldsymbol{T}_{\boldsymbol{p} 2} \\
\left({ }^{\circ} \mathbf{K}\right)\end{array}$ & $\begin{array}{c}\mathbf{T}_{\mathbf{p} 3} \\
\left({ }^{\circ} \mathbf{K}\right)\end{array}$ & $\begin{array}{c}\Delta \boldsymbol{H}_{\mathbf{1}} \\
(\mathbf{J} / \mathbf{g})\end{array}$ & $\begin{array}{c}\Delta \boldsymbol{H}_{\mathbf{2}} \\
(\mathbf{J} / \mathbf{g})\end{array}$ & $\begin{array}{c}\Delta \boldsymbol{H}_{\mathbf{3}} \\
\mathbf{J} / \mathbf{g})\end{array}$ \\
\hline MS-LO & 666 & 681 & 718 & 769 & 907 & $-6,9$ & $-28,9$ & $-14,9$ \\
\hline MS-HO & & 669 & 725 & 773 & 920 & -35.8 & $-20,8$ \\
\hline SC-LO & 685 & 692 & 719 & 768 & 867 & $-4,1$ & $-29,6$ & $-18,0$ \\
\hline SC-HO & - & 664 & 735 & 772 & 938 & $-60,2$ & \\
\hline
\end{tabular}

Figure 3 shows SEM micrographs of the bulk alloys observed on polished cross sections of rods. In the case of SC-LO sample (Fig. 3a,b) only fine oxides were observed without any other crystalline phases. The size and number of oxides in the SC-HO sample, synthesized from high oxygen zirconium, were much bigger (compare Fig. 3b,d). SEM-EDS analysis of oxides (Fig. 4) confirmed the $\mathrm{Y}_{2} \mathrm{O}_{3}$ phase. Moreover crystalline dendritic areas were observed (Fig. 3c), as previously revealed by XRD analysis.

Hardness measurements and uniaxial compression testing at a strain rate of $1 \times 10^{-4} \mathrm{~s}^{-1}$ were carried out on the suction-cast alloys. Vickers hardness of the amorphous phase was close to $500 \mathrm{HV} 1$ in both samples, SC-LO and SC-HO. In the latter, the hardness of the crystalline areas was about 445 HV1 (Table 2). Figure 5 illustrates room temperature compressive engineering stress-strain curves of the suction-cast rods. The compressive strength of the SC-LO and SC-HO samples was about 1684 noticed on the strain-stress curves. The standard deviation of the partially crystalline alloy was much larger, due to a non-uniform distribution of the crystalline phases. One of the SC-HO samples broke at a compressive stress of only $1200 \mathrm{MPa}$.

TABLE 2

Mechanical properties of the suction-cast alloys

\begin{tabular}{|l|c|c|}
\hline \multirow{2}{*}{\multicolumn{1}{|c|}{ Property }} & \multicolumn{2}{c|}{ Sample designation } \\
\cline { 2 - 3 } & SC-LO & SC-HO \\
\hline Compressive strength (MPa) & $1684 \pm 11$ & $1431 \pm 255$ \\
\hline Hardness HV1 in amorphous areas & $491 \pm 6$ & $497 \pm 6$ \\
\hline Hardness HV1 in crystalline areas & - & $445 \pm 31$ \\
\hline
\end{tabular}

\section{Discussion}

Microstructure investigations of suction-cast rods revealed formation of crystalline yttrium oxides, both in SC-LO and SC-HO samples. XRD studies (Fig. 1) did not confirm their presence, due to its relatively low volume fraction. These oxides are known to trap oxygen and allow formation of the amorphous phase. The melting point of $\mathrm{Y}_{2} \mathrm{O}_{3}$ is about $2430^{\circ} \mathrm{C}$ [27], which means that oxides were dissolved during arc melting and were formed again upon solidification. Rare earth elements act as oxygen scavengers to purify the molten liquid, to a certain extent, and enable the formation of the glass matrix in BMGs. However, 

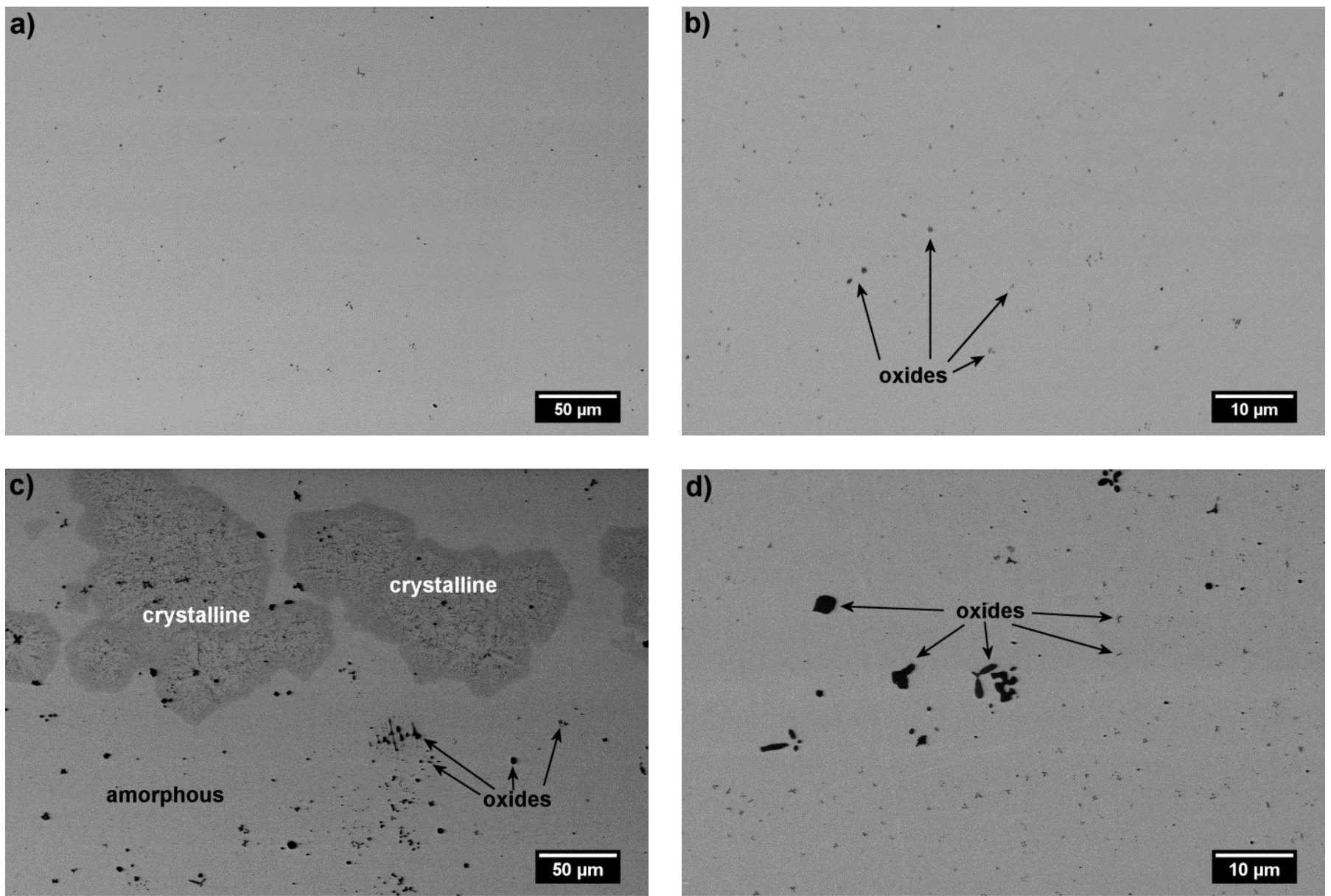

Fig. 3. SEM-BSE images of the cross sections of suction-cast $\mathrm{Cu}_{46} \mathrm{Zr}_{42} \mathrm{Al}_{7} \mathrm{Y}_{5}$ alloys: a,b) SC-LO, c,d) SC-HO
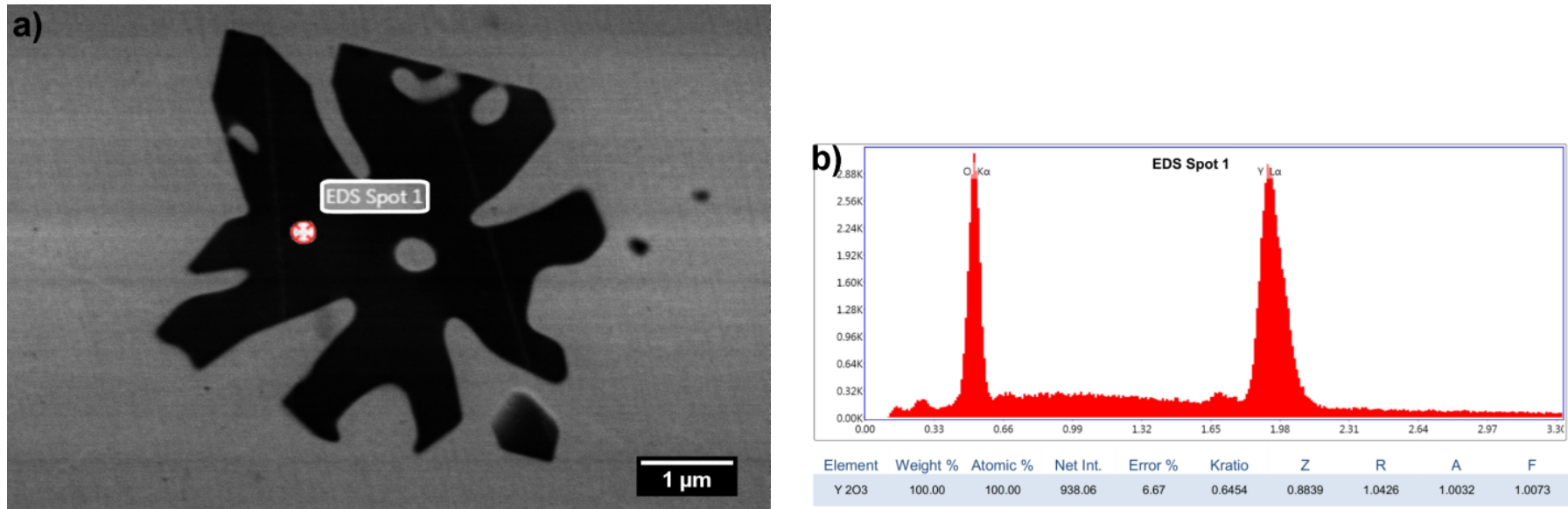

Fig. 4. a) SEM-BSE image of the oxide particle observed in the SC-HO sample and b) corresponding EDS spectrum

in order to get the desired positive effect of REE addition, its concentration should correspond to close-to-stoichiometric level with the oxygen content to form stable oxides [15]. On the other hand, oxides acted as nucleation sites of other crystalline phases upon solidification, which led to partial crystallization of the SC-HO alloy. Presence of oxides significantly reduces thermal stability of the amorphous phase during heating. Consequently, no glass transition temperatures could be detected on the DSC curves for MS-HO and SC-HO samples (Fig. 2). The supercooled liquid region was detected only in the samples synthesized from low oxygen $\mathrm{Zr}$ (SC-LO), but was much smaller compared to other reports [28,29].

The high purity of raw materials in glass-forming alloys is an important factor in obtaining the desired chemical composition of alloys. However, oxygen content in raw materials, especially in those exhibiting high chemical affinities for oxygen, like $\mathrm{Zr}$, seems to play a more important role in formation and thermal stability of the amorphous phase. 


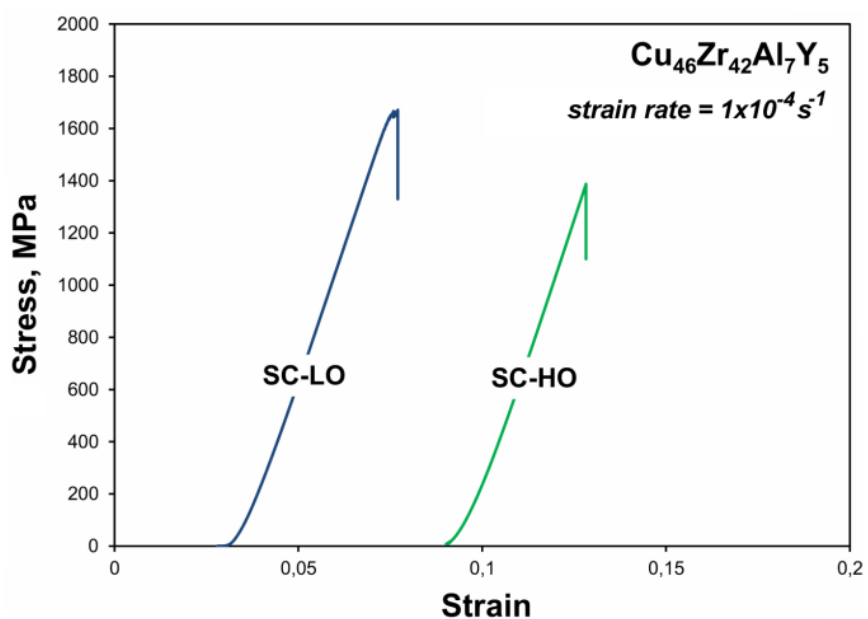

Fig. 5. Typical room temperature compressive stress-strain curves of the suction-cast alloys. The curves are shifted along the strain axis for better visibility

\section{Conclusions}

The oxygen content in glass-forming alloys is a very important factor, particularly in formation of bulk metallic glasses. No significant effect of oxygen content on the structure of rapidly cooled melt-spun ribbons was noticed, but calorimetric studies pointed out different crystallization behaviour of both initially amorphous ribbons.

Despite low nominal purity of $\mathrm{Zr}$ crystal bar (99.5\%), amorphous $3 \mathrm{~mm} \mathrm{Cu}_{46} \mathrm{Zr}_{42} \mathrm{Al}_{7} \mathrm{Y}_{5}$ alloy rod was obtained, which is attributed to relatively low oxygen content in the alloy. The presence of fine yttrium oxides did not cause crystallization of this alloy upon solidification, but significantly reduced thermal stability of the amorphous phase. Partial crystallization of the same alloy synthesized from high oxygen $\mathrm{Zr}$ (SC-HO) was reported, despite higher nominal purity of $\mathrm{Zr}(99.8 \%)$.

A mean compressive strengths of the SC-LO and SC-HO samples were $1684 \pm 11 \mathrm{MPa}$ and $1431 \pm 255 \mathrm{MPa}$, respectively. The large standard deviation of the compressive strength for the SC-HO samples results from a non-homogeneity of the partially crystalline alloy.

\section{Acknowledgements}

This work was financially supported by the National Science Centre (NCN) under contract No. 2011/03/D/ST8/04131. Valuable contribution of Marcelo Falcão de Oliveira (Universidade de São Paulo, Brasil) to the oxygen analysis of $\mathrm{Zr}$ metal is acknowledged. Appreciation is also expressed to Prof. A.S. Wronski (University of Bradford, UK) for editing the manuscript.

\section{REFERENCES}

[1] A. Inoue, A. Takeuchi, Acta Mater. 59, 2243 (2011).

[2] J. Latuch, P. Krzesniak, T. Kulik, J. Alloy Compd. 483, 47 (2009).

[3] A. Inoue, X. Wang, W. Zhang, Rev. Adv. Mater. Sci. 18, 1 (2008).

[4] C.L. Dai, H. Guo, Y. Shen, Y. Li, E. Ma, J. Xu, Scripta Mater. 54, 1403 (2006).

[5] B.W. Zhou, X.G. Zhang, W. Zhang, H. Kimura, T. Zhang, A. Makino, A. Inoue, Mater. Trans. JIM 51, 826 (2010).

[6] M.W. Chen, A. Inoue, T. Sakurai, D.H. Ping, K. Hono, Appl. Phys. Lett. 74, 812 (1999).

[7] T.B. Massalski, H. Okamoto, P.R. Subramaniam, L. Kacprzak, ASM Int. 3, 1990.

[8] A. Gebert, J. Eckert, L. Schultz, Acta Mater. 46, 5475 (1998).

[9] D.V. Louzguine-Luzgin, C. Suryanarayana, T. Saito, Q.S. Zhang, N. Chen, J. Saida, A. Inoue, Intermetallics 18, 1531 (2010).

[10] C.T. Liu, M.F. Chisholm, M.K. Miller, Intermetallics 10, 1105 (2002).

[11] M.L. Vaillant, T. Gloriant, I. Thibon, A. Guillou, V. Keryvin, T. Rouxel, D. Ansel, Scripta Mater. 49, 1139 (2003).

[12] X.H. Lin, W.L. Johnson, W.K. Rhim, Mater. Trans. JIM 38, 473 (1997).

[13] W.H. Wang, Prog. Mater. Sci. 52, 540 (2007).

[14] L. Deng, B. Zhou, H. Yang, X. Jiang, B. Jiang, X. Zhang, J. Alloy Compd. 632, 429 (2015).

[15] A.A. Kündig, D. Lepori, A.J. Perry, S. Rossmann, A. Blatter, A. Dommann, P.J. Uggowitzer, Mater. Trans. JIM 43, 3206 (2002).

[16] J. Luo, H. Duan, C. Ma, S. Pang, T. Zhang, Mater. Trans. JIM 47, 450 (2006).

[17] Y.X. Wang, H. Yang, G. Lim, Y. Li, Scripta Mater. 62, 682 (2010).

[18] J.L. Cheng, G. Chen, Z.W. Zhang, Z.Z. Wang, Z.Y. Wang, X.Q. Li, Intermetallics 49, 149 (2014).

[19] J.L. Cheng, G. Chen, C.T. Liu, Y. Li, Scientific Reports 3, 2097 (2013).

[20] J. Cheng, G. Chen, Mater. Lett. 118, 169 (2014).

[21] K. Ziewiec, Z. Kędzierski, A. Zielińska-Lipiec, J. Stępiński, S. Kąc, J. Alloy Compd. 482, 114 (2009).

[22] K. Górecki, P. Bała, G. Cios, T. Kozieł, M. Stępień, K. Wieczerzak, Metal. Mater. Trans. A 47A, 3257 (2016).

[23] K. Wieczerzak, P. Bała, M. Stępień, G. Cios, T. Kozieł, Mater. Des. 94, 61 (2016).

[24] K.T. Park, T.H. Lee, N.C. Jo, H.H. Nersisyan, B.S. Chun, H.H. Lee, J.H. Lee, J. Nucl. Mater. 436, 130 (2013).

[25] A. Inoue, S. Tsutomu, Z. Tao, Mater. Trans. JIM 36, 1420 (1995).

[26] T. Kozieł, Arch. Metall. Mater. 60, 767 (2015).

[27] M. Kenisarin, V.Y. Checkhovskoy, Rev. Int. Hautes Temp. 12, 329 (1975).

[28] D. Xu, G. Duan, W.L. Johnson, Phys. Rev. Lett. 92, 24501 (2004).

[29] H.W. Xu, Y.L. Du, Y. Deng, T. Nonferr. Metal. Soc. 22, 842 (2012). 